\title{
Tropical-Extratropical Climatic Teleconnections: A Long-Term Perspective
}

\author{
Chapman Conference, Honolulu, Hawail, 8-11 February 2005
}

Climatic teleconnections link regional variations to global phenomena. An excellent example of this is the impact that variations in EI Niño Southern Oscillation (ENSO) have on global climatic anomalies.

The purpose of this conference was to bring together atmospheric scientists, oceanographers and paleoclimatologists in order to provide modern climate scientists with a better understanding of paleoclimate records, and paleoclimatologists with the opportunity to place their records into the larger context of climate processes. Climate periods reconstructed using proxy records from ocean, lake and peat sediments, fossil corals, ice cores, speleothems, paleosols and tree rings included the last millennium, the Quaternary, and the Pliocene-Miocene. Variability on millennial and orbital time scales is apparent in many of these records and they show tropicalextratropical connections but forcings can be different. Millennial variability in tropical SST records corresponds to prominent features in the North Atlantic (e.g. Younger Dryas) but have a muted response in the western tropical Pacific. Wellpreserved corals in eastern Indonesia record a cooling event over $\sim 100$ years synchronous with the $8.2 \mathrm{ka}$ cold event in the North Atlantic, supporting the role of atmospheric teleconnections in rapidly propagat-

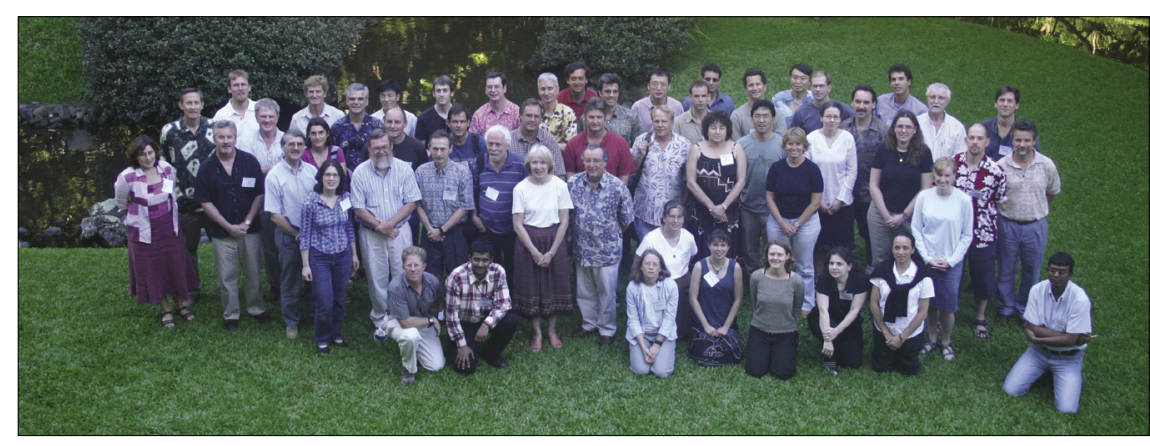

Fig. 1: The conference brought together experts in observation, theory and modeling of modern teleconnections, and in analysis of past records of climate variability.

ing this signal to the tropics. The paleoclimate record of the Asian summer monsoon winds shows robust teleconnections with ENSO and North Atlantic climate. Antarctic ice cores show variability that may be tied to variability of moisture sources at low latitudes.

The reports on modern climate using observational diagnostic analysis and modeling results provided a basis for understanding the paleoclimate records. The global heat budget provides strong constraints on the climate system by requiring systematic movement of energy. Latent heating in precipitation dominates the patterns of atmospheric heating and teleconnections. Monsoons are a coupled atmosphere-ocean-land phenomena and are characterized by a strong cross-equatorial pressure gradient. Teleconnections originating from patterns of tropical SST change and variability are sensitive to a change of ENSO variance and to the patterns of warming in the tropical Pacific and Indian Oceans. Oceanic thermohaline circulation was also shown to be important.

The interdisciplinary mix of researchers from eight countries led to lively discussions and provocative questions, and new collaborations have already been forged to study the climate system from a longerterm perspective. Future meetings are being planned to continue to bring paleo-proxy and instrumental data, and climate modeling of the past, present and future to bear on the nature of climate change.

\section{ACKNOWLEDGMENTS}

This conference was sponsored by the International Pacific Research Center, the US National Science Foundation and PAGES.

BetTe 0tT0-Bliesner NCAR, Boulder, USA ottobli@ucar.edu

\section{An Overview of the Swiss Contribution to the HITE Project}

\section{HITECH WORKSHOP 2004, ZuRich, SWitZerLAND, 18 October 2004}

Human Impacts on Terrestrial Ecosystems (HITE) - an initiative of IGBP-PAGES - is an international network of projects devoted to the study of ecosystem changes on decadal-to-millennial time scales. The Swiss contribution to HITE comprises a cluster of five projects, the "HITECH-Net", where "CH" stands for Confoederatio Helvetica, Latin for "Swiss Federation".

A major HITECH workshop entitled “Using modeling, paleo archives, historical and contemporary information to assess present and future ecosystem dynamics" took place in mid-October 2004 at ETH Zurich. This one-day workshop comprised four keynote lectures, eleven contributed presentations and several posters. Participants were mostly from Switzerland but also included scientists from the UK, Germany, France, Austria and Italy. Presentations were grouped into four chronological sessions, each beginning with a keynote lecture.

The first session focused on long time scales and the early history of human impacts on ecosystems.

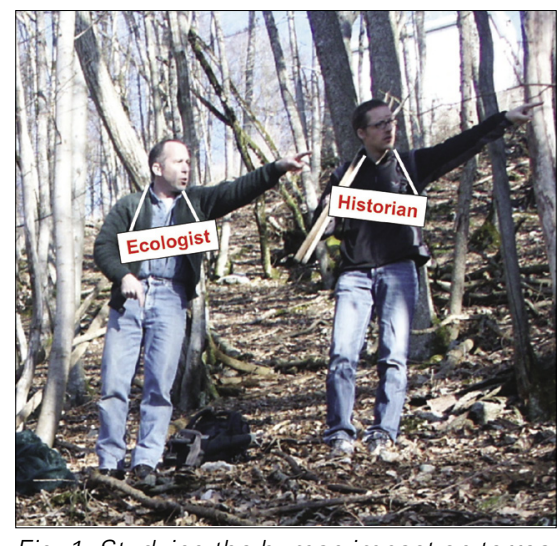

Fig. 1: Studying the human impact on terrestrial ecosystems requires an interdisciplinary approach! 
B. Ammann (University of Bern) gave an overview of methods and approaches in paleoecology. Subsequent presentations covered topics such as tree migration, impacts of climate and humans on vegetation changes, and reconstruction of historical fire regimes. The second session focused on the historical time scale. M. Bürgi (WSL, Birmensdorf) showed how environmental history and historical ecology extend paleoecological approaches up to the present time. Other presentations focused on past disturbance patterns in forest ecosystems, with an analysis of fire history and ecology. In the afternoon, J. Dearing (HITE
Leader, University of Liverpool, UK) presented the Lac d'Annecy project in France, a study of the impact of changes in historical land use and climatic shifts on sediment deposition. Other presentations on linking past with present ecosystem dynamics included approaches using aerial photographs, tree rings and genetic markers. The last session focused on assessing future ecosystem dynamics using modeling. $\mathrm{H}$. Bugmann (Swiss Federal Institute of Technology Zurich) discussed how approaches for evaluating past ecosystem dynamics could be used to project future trajectories of terrestrial systems. Case studies covered predicting future fire regimes and using models of insect outbreaks to derive sustainable management strategies.

The workshop revealed a wealth of approaches and data sources and illustrated the importance of an integrated approach. The need for multi-site studies, meta-analyses and comparative approaches was also recognized.

For more information see: www.wsl.ch/HITECH.

\section{MATTHIAS BüRGI}

WSL, Birmensdorf, Switzerland matthias.buergi@wsl.ch

\section{Past Ecosystem Processes and Human-Environment Interactions}

Pages Focus 5 Conference, Buellton, California 13-18 February 2005

PAGES Focus 5 is composed of three distinct but complementary sub-programs that focus on the human dimensions of environmental change: Human Impacts on Terrestrial Ecosystems (HITE), Land Use and Climate Impacts on Fluvial Systems (LUCIFS) and Human Impacts on Lake Ecosystems (LIMPACS). Program leaders and around 30 scientists representing 14 countries met for 4 days in February to discuss research findings and the future development of the program.

J. Anderson, R. Dikau and H. Bugmann led days dedicated to oral and poster summaries within the subprograms, and John Dearing led a further day of presentations and discussion about modeling and integration. Talks and posters ranged from modern and historical flooding in the Mississippi catchment, to the causes of eutrophication in Lough Neagh and the sustainability of mangrove forest. M.-J. Gaillard ran a workshop on POLLENDCAL, the calibration of pollen diagrams in terms of land cover. C. Crumley chaired a session on how to enhance links between the social and natural sciences.

Over twelve hours of lively debate identified a number of areas where Focus 5 could be developed, particularly concerning integration and regionalization of research outputs. $A$ new integrative scheme for organizing Focus 5 science was proposed. It

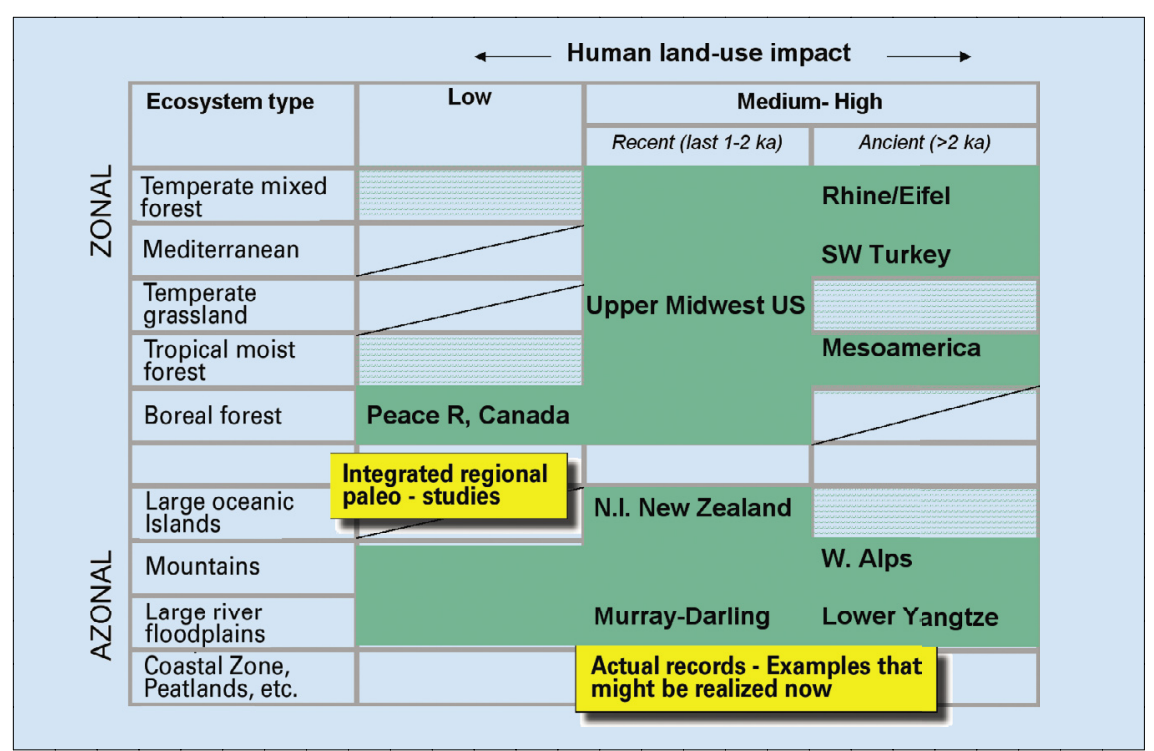

Fig. 1: Proposed matrix for regionalization of global case studies with geographical examples. emphasizes the synthesis of data and findings from multiple case studies for specific areas of the world. These syntheses will provide the long temporal perspective on the functioning and sustainability of specific regions. A simple matrix of zonal/azonal areas and the degree of previous human impact will provide the basic organizational structure (Fig. 1).

In practice, it is likely that regional groups will nominate their work for inclusion, and Focus 5 will encourage syntheses where they are required and new research where none exists. A number of flagship studies combining archives (e.g., sedimentary, documentary, instrumental) will be promoted as demonstration projects. The new scheme will be launched at the PAGES OSM. This meeting was a rare opportunity for Focus 5 scientists to meet as a single group and achieved a great deal, especially in terms of integration. It served to emphasize the diversity of environmental issues and topics that Focus 5 lends itself to, and the clear need to learn from the past in order to understand the present.

Thanks to Isabelle Larocque for organizing the meeting and to all the participants for their full contributions.

\section{John Dearing}

University of Liverpool, UK j.dearing@liverpool.ac.uk 